\title{
POTENTIALLY CURATIVE MULTIVISCERAL RESECTIONS FOR LOCALLY ADVANCED COLORECTAL CANCER
}

\author{
Vesselin Marinov \\ Minimally Invasive and Laparoscopic Surgery, HPB and General Surgery Clinic, \\ Tokuda Hospital Sofia
}

\begin{abstract}
BACKGROUND: Performing multivisceral resections in locally advanced colorectal cancer is the only way to achieve surgical radicality in the treatment of this disease. The frequency of such cases remains high as a result of the global increase in morbidity and poor health culture of the population. Locally advanced colorectal cancer has exclusive specificity in terms of its location - upper abdominal floor, pelvic area and requires multidisciplinary surgical skills and experience. Early perioperative results in 128 cases of potentially curative multivisceral resections are reported in this publication.
\end{abstract}

AIM: To assess the early perioperative results in patients with multivisceral resections in cases of advanced colorectal cancer.

MATERIALS AND METHODS: For a period of 8 years: 2007 - 2014, 191 patients with advanced colorectal cancer were operated on. In 128 cases multivisceral resections were performed in attempt to achieve surgical radicalism.

RESULTS: The average age in the group was 66.7 years. The perioperative mortality amounted to $3.1 \%$ (4 patients). Perioperative complications were observed in 25 (19.5\%) patients.

CONCLUSION: Surgery is the only method to achieve long-term survival in patients with advanced colorectal cancer. The performance of multivisceral resections is challenging for the surgeon and often a multidisciplinary approach is needed.

Keywords: multivisceral, locally advanced, colorectal

\section{INTRODUCTION}

Despite the advanced imaging and endoscopic diagnostic techniques, locally advanced diseases are found during surgical exploration. The differentiation of macroscopic tumor infiltration to adjacent organs and anatomical structures from peritumoral inflammation is very difficult, sometimes even impos-

Address for correspondence:

Vesselin Marinov

51B Nikola Vaptsarov Blvd

$4^{\text {th }} \mathrm{fl}$. Surgery Dept.

Tokuda Hospital Sofia

1612, Sofia, Bulgaria

e-mail:vesika_m@mail.bg

Received: November 15, 2015

Accepted: February 12, 2016 sible. Multivisceral resections are often performed in an attempt to achieve surgical radicalism. With the presence of obstructive and inflammatory complications, and solitary liver and peritoneal metastases, the surgeon is placed in a situation of difficult choice in regard to the surgical strategy.

\section{MATERIALS AND METHODS}

191 patients with locally advanced CCR were operated on in the Department of Hepatobiliary, Pancreatic and General Surgery at "Tokuda Hospital Sofia" during the period of January 01, 2007 - December 31, 2014. Surgery with the aim of achieving surgical radicalism patients was performed in 128 . All types of research methods - clinical, laboratory, imaging, instrumentation, etc. are used in the course of the study. Retro- and partially prospective anal- 
yses of the perioperative results for the period of 8 years were made.

\section{RESULTS}

Colorectal cancer is a disease the incidence of which increases with age. The average age in the study group was 66.7 y.o. - the oldest patient was 91 y.o., and the youngest was 38 y.o. The gender distribution of the patients showed a slight prevalence of men $52.3 \%$ to $47.7 \%$ of women.

Localizations of the pathological process are shown in Table. 1. versal colon, left flexure - 27. Here (less than $1 / 4$ of all cases) is the largest observed polymorphism of damage to adjacent organs and anatomical structures stomach EHBT, bladder, liver, duodenum, pancreas, spleen, diaphragm, main vessels, pericardium, omentum, adrenal glands. This is due to the relatively asymptomatic increase in tumor formation, and late onset of symptoms, some of which are caused by the neighboring organs. Table 2 shows the rate of involvement of organs and anatomical structures.

The most commonly affected anatomical struc-

Tabl. 1 Localizations of the pathological process

\begin{tabular}{c|c|cc|ccc|c|}
$\begin{array}{c}\text { Right } \\
\text { hemicolon }\end{array}$ & $\begin{array}{c}\text { Right } \\
\text { flexure }\end{array}$ & $\begin{array}{c}\text { Transverse } \\
\text { colon }\end{array}$ & $\begin{array}{c}\text { Left } \\
\text { flexure }\end{array}$ & $\begin{array}{c}\text { Descendent } \\
\text { colon }\end{array}$ & $\begin{array}{c}\text { Sigmoid } \\
\text { colon }\end{array}$ & $\begin{array}{c}\text { Sigmoid- } \\
\text { rectal colon }\end{array}$ & Rectum \\
\hline
\end{tabular}

35

8

5

14

7

34

10

15

As it is seen, the most frequent localization of LACRC is in the right hemicolon, because the caecum and the ascendant colon have a tendency of involving adjacent organs and anatomical structures. On other hand, the LACRC of the left hemicolon, combined with the LACRC of the rectum amount to 66 in total (51.5\%). Of particular interest is the group of patients with locally advanced disease in the area of the upper abdominal floor - right flexure, trans- ture is the parietal peritoneum of the anterior abdominal wall and the lateral channels with/without infiltration of the muscle-aponeurotic layers of the wall. Relatively often, involvement of the small intestine and infiltration of the retroperitoneal space is observed. In almost all cases of locally advanced carcinoma of the left flexure of the colon there was macroscopic evolvement of the spleen or its chyle, and the tail of the pancreas. The highest incidence of infiltra-

Tabl. 2 Rate of involvement of organs and anatomical structures

\begin{tabular}{lcll}
\multicolumn{1}{c}{ Organs and anatomical structures } & & Organs and anatomical structures & \\
Parietal peritoneum & 62 & Liver & 4 \\
Small bowel & 19 & Omentum majus & 4 \\
Gall bladder & 4 & Adrenal glands & 1 \\
Mesenterium & 9 & Pericardium & 1 \\
Mesenteric vessels & 2 & Iliac vessels & 1 \\
Retroperitoneum & 18 & Uterus & 7 \\
Spleen & 11 & Vagina & 5 \\
Pancreas & 12 & Ureter & 4 \\
Diaphragm & 2 & Urinary bladder & 20 \\
Adipose capsule of kidney & 10 & Adnexa & 8 \\
Large bowel & 8 & Spermatic vessels & 4 \\
Kidney & 1 & Presacral fascia & 1 \\
Appendix & 3 & M. ileopsoas & 1 \\
Stomach & 4 & D. deferens & 3 \\
Duodenum & 2 & & \\
\hline
\end{tabular}


tion of an adjacent organ was the urinary bladder by carcinomas in the left side of the colon and the rectum, with/without signs of urinary infection.

Complications were observed in 63 patients at the time of the diagnosis. The most common manifestation was bowel obstruction (of which full one in 9 patients and relative - in 27). In 11 patients pericolic abscess was diagnosed. Ascites, segmental intestinal ischemia, retroperitoneal abscess, paraaortic metastatic lymph nodes with infiltration of the lower vena cava, hydronephrosis, diffuse peritonitis, gastro-duodenal fistulae, colo-, sigmo- and rectovesical fistula, rectovaginal fistula were observed less often.

All patients in the study group underwent sustained colonic cancer resection with regional lymphadenectomy, excision or resection of macroscopically involved in the process anatomical structures and organs, synchronous liver resection and peritoneal metastasectomy in solitary metastases. Surgical interventions were completed without residual macroscopic pathologic tissue. The principles that guided us in determining our surgical strategy to perform potentially curative interventions are:

- Local resectability in potential tumor cells, free resection margins

* In all cases of macroscopic involvement of the neighboring organs and/or anatomical structures - we have performed a resection/excision of the same undistorted, adherent to the tumor surface

* Synchronous resectable liver metastases

* Synchronous solitary resectable peritoneal metastases

* Lack of distant lymphogenic metastases
* Lack of distant dissemination - extraperitoneal

- Satisfactory general performance status of the patient.

The volume of surgery depends on the degree of infiltration of adjacent anatomical structures and organs. In most cases, colonic intervention with excision of the parietal peritoneum was performed. Special attention should be paid to four cases of en bloc resection:

1. Right hemicolectomy, distal resection of the stomach, duodenal partial resection, partial resection of the pancreatic head, resection with reconstruction of the superior mesenteric vein.

2. Left hemicolectomy, splenectomy, distal pancreatectomy, proximal resection of the stomach, resection of the left dome of the diaphragm, resection of the pericardium.

3. Right hemicolectomy, excision of the anterior abdominal wall, resection of the stomach, duodenum, atypical liver resection, partial resection of the pancreas.

4. Frontal resection of the rectum, resection and ligation of the left internal iliac vessels, resection of the left ureter with UCNS.

The operative time ranged between 90 and 480 min. Perioperative mortality amounted to $3.1 \%$ (4 patients). Perioperative complications were observed in $19.5 \%$ (25 patients). The postoperative complications are presented in Table. 3

The complications after en bloc resection of LACRC, can be heterogeneous and depend on the localization of the CRC and the adjacent organs.

Tabl. 3. Postoperative complications

\begin{tabular}{|c|c|c|c|}
\hline Type & & Type & \\
\hline Wound infection & 9 & Pancreatic fistula III deg. & 1 \\
\hline Partial anastomotic leakage without re-operation & 2 & Duodenal stump insufficiency without re-operation & 1 \\
\hline Acute psychosis & 2 & Arrhythmia & 1 \\
\hline Wound seroma & 3 & Severe bronchitis & 1 \\
\hline Postoperative incomplete bowel obstruction & 2 & Postoperative ulcer perforation & 1 \\
\hline Urine retention & 1 & Pneumonia with $\mathrm{ABI}$ & 1 \\
\hline Iatrogenic spleen trauma & 1 & Thrombocytosis after splenectomy & 1 \\
\hline Postoperative pelvic hemorrhage & 1 & & \\
\hline
\end{tabular}




\section{DISCUSSION}

Colorectal carcinoma is one of the most common diseases requiring surgical intervention. The involvement of adjacent organs and anatomical structures, which occurs in 5 to $20 \%$ of the cases, is challenging for the surgical team. In these cases performing multivisceral resection is the best surgical strategy for the treatment of T4 LACRC $(1,2,3,4,5)$.

In the literature there are quite conflicting data on the association of multivisceral resections with higher percentage of complications. Most of the studies report an acceptable level of perioperative complications, almost the same as those in T3 resection $(1,6,7,8)$. On the other hand, some authors reported perioperative morbidity rates between 33 and $50 \%(9,10)$. In one study, Gezem et al. reported levels of perioperative complications and mortality from $24.4 \%$ and $4.4 \%$, respectively (11). In a national survey conducted among the French population, Mitry et al. report perioperative mortality rate of $6.2 \%$ (12). In this study, perioperative complication rates and mortality were $19.5 \%$ and $3.1 \%$, respectively. Special attention is paid in cases with locally advanced disease in the supramesocolic part of the abdomen, where skills in HPB surgery are required (13).

\section{CONCLUSION}

Multivisceral resections have proven to be the best choice for the treatment of T4 CRC. Data available in the literature as well as ours present acceptable perioperative morbidity and mortality rates. Experience in hepatobiliary and pancreatic surgery is extremely important in the treatment of advanced cases located in the upper abdominal floor. The worldwide recommendations are such patients to be treated in specialized centers with multidisciplinary approach and by experienced surgical teams. Data from a comparative analysis of this group of patients and other patients who have undergone palliative multivisceral resection, palliative procedures and have T3 tumors, and an analysis of their longterm survival is to be presented.

\section{REFERENCES}

1. Gebhardt C, Meyer W, Rukriegel S, Merier U. Multivisceral resection of advanced colorectal carcinoma. Langenbeck's Arch Surg. 1999;384:194-9. doi: 10.1007/s004230050191.
2. Luna-Perez P, Rodoriguez-Ramirez SE, Barrera MG, Zeferino M, Labastida S. Multivisceral resection for colon cancer. J Surg Oncol. 2002;80:100-4. doi: 10.1002/jso.10105.

3. Lehnert T, Methner M, Pollok A, Schaible A, Hinz U, Herfarth C. Multiviscerral resection for locally advanced primary colon and rectal cancer. An analysis of prognostic factors in 201 patients. Ann Surg. 2002;235:217-25.

4. Devine R, Dozois R. Surgical management of locally advanced adenocarcinoma of the rectum.World J Surg. 1992;16:486-489. doi: 10.1007/BF02104452.

5. Staib L, Link KH, Blatz A, Berger HG. Surgery of colorectal cancer: surgical morbidity and five- and ten-year results in 2400 patients -- monoinstitutional experience. World J Surg. 2002;26:59-66. doi: 10.1007/s00268-001-0182-5.

6. Izbicki JR, Hosch SB, Knoefel WT, Passlick B, Bloechle C, Broelsch CE. Extended resections are beneficial for patients with locally advanced colorectal cancer. Dis Colon Rectum. 1995;38:1251-6. doi: 10.1007/BF02049148.

7. Montesani C, Ribotta G, De Milito R, Pronio A, D’Amato A, Narilli P, Jaus M. Extended resection in the treatment of colorectal cancer. Int J Colorectal Dis. 1991;6:161-4. doi: 10.1007/BF00341238.

8. Poeze M, Houbiers JG, van de Velde CJ, Wobbes T, von Meyenfeldt MF. Radical resection of locally advanced colorectal cancer. Br J Surg. 1995;82:138690. doi: 10.1002/bjs.1800821031.

9. Lehnert T, Methner M, Pollok A, Schaible A, Hinz U, Herfarth C. Multiviscerral resection for locally advanced primary colon and rectal cancer. An analysis of prognostic factors in 201 patients. Ann Surg. 2002;235:217-25.

10. Amshel C, Avital S, Miller A, Sands L, Marchetti F, Hellinger M. T4 rectal cancer: analysis of patient outcome after surgical excision. Am Surg. 2005;71:901-4.

11. Gezen C, Kement M, Altuntas YE, Okkabaz N, Seker M, Vural S, Gumus M, Oncel M. Results after multivisceral resections of locally advanced colorectal cancers: an analysis on clinical and pathological t4 tumors. World J Surg Oncol. 2012Feb $15 ; 10: 39$

12. Mitry E, Bouvier AM, Esteve J, Fivre J. Benefit of operative mortality reduction on colorectal cancer survival. Br J Surg. 2002;89:1557-62. doi: 10.1046/j.1365-2168.2002.02276.x. 
13. Marinov V, Gaydarski R, Draganov K, Katev N.N, Rusenov D, Kolev Y, Petreska A, Borisov B, Chengalova G, Lavchev S, Penchev D, Stoyanova D, Tonev S. Locally advanced adenocarcinoma of the supramesocolic part of the colon. Features of surgical treatment and challenges. Scripta Scientifica Medica, vol. 45, Suppl. 2, 2013, pp. 79-85 